\title{
Efeito do Lodo de Esgoto na Indução de Supressividade in vitro a Phytophthora nicotianae*
}

\author{
Carolina Leoni ${ }^{1 * *}$ \& Raquel Ghini ${ }^{2 * *}$ \\ ${ }^{1}$ Sección Protección Vegetal, Estación Experimental Las Brujas, Instituto Nacional de Investigación Agropecuaria, \\ CEP 90200, Rincón del Colorado, Canelones, Uruguay, fax: 5982 3677609, e-mail: cleoni@inia.org.uy; ${ }^{2} E m b r a p a$ \\ Meio Ambiente, Cx. Postal 69, CEP 13.820-000, Jaguariúna, SP, e-mail: raquel@cnpma.embrapa.br
}

(Aceito para publicação em 26/09/2002)

Autor para correspondência: Carolina Leoni

LEONI, C. \& GHINI, R. Efeito do lodo de esgoto na indução de supressividade in vitro a Phytophthora nicotianae. Fitopatologia Brasileira 28:067-075. 2003.

\section{RESUMO}

Uma alternativa de manejo das doenças causadas por Phytophthora spp. é o uso de matéria orgânica. No presente trabalho foi avaliada a potencialidade do lodo de esgoto na indução de supressividade in vitro a $P$. nicotianae. O efeito do lodo de esgoto incorporado ao solo na sobrevivência de $P$. nicotianae foi avaliado mediante um experimento fatorial com dois fatores: doses de lodo de esgoto $(0,10,20$ e $40 \%$ p/p) e concentrações de inóculo [0,10 ou $20 \mathrm{~g}$ de grãos de trigo (Triticum aestivum) colonizados $\mathrm{kg}^{-1}$ ]. Aos 21 dias, quando aumentaram as doses de lodo de esgoto, a sobrevivência de $P$. nicotianae e os pHs das misturas diminuíram, e as condutividades elétricas (CE) aumentaram. As correlações entre a CE e a sobrevivência do patógeno foram negativas e significativas $(\mathrm{P}>0,05)$. Para estudar o efeito dos compostos químicos envolvidos na supressividade, foram obtidos extratos em água, $\mathrm{H}_{2} \mathrm{SO}_{4} 2 \mathrm{~N}$ e $\mathrm{KOH} 0,4 \mathrm{~N}$ de misturas de areia - lodo de esgoto $(20 \% \mathrm{p} / \mathrm{p})$, e foram acrescentados ao meio de cultura e seu efeito avaliado no crescimento das colônias de $P$. nicotianae. $\mathrm{O}$ extrato ácido $\left(\mathrm{H}_{2} \mathrm{SO}_{4} 2 \mathrm{~N}\right)$ do tratamento com $20 \%$ de lodo de esgoto inibiu significativamente $(\mathrm{P}>0,05)$ o crescimento da colônia do patógeno. $\mathrm{O}$ efeito biológico foi estudado mediante isolamento de microrganismos em meio de cultura e seleção por antagonismo. No bioensaio com plântulas de alfafa (Medicago sativa) destacaram-se os isolados F9.1 (Aspergillus sp.) e A12.1 (actinomiceto, não identificado); e no teste de culturas pareadas destacou-se um Trichoderma sp. e dois actinomicetos por antibiose, e um Trichoderma sp. e três Aspergillus sp. por hiperparasitismo.

Palavras-chave adicionais: matéria orgânica, biossólidos.

\section{ABSTRACT}

\section{Effect of sewage sludge in vitro to suppress Phytophthora nicotianae}

Soil organic matter amendments may provide an alternative management practice for soil diseases caused by Phytophthora spp. In this paper we have evaluated the effectiveness of residential sewage sludge to suppress $P$. nicotianae under laboratory conditions. The effect of sewage sludge on $P$. nicotianae survival was evaluated by two experimental factors: sewage sludge doses $(0,10,20$ and $40 \%$ $\mathrm{w} / \mathrm{w}$ ) and inoculum level [0, 10 and $20 \mathrm{~g}$ infested wheat (Triticum aestivum) seeds per $\mathrm{kg}$ of soil]. After maintaining the mixtures (soil sewage sludge - inoculum) at room temperature for 21 days, treatments with higher organic matter had lower $P$. nicotianae survival, $\mathrm{pH}$ of the mixture, and higher electric conductivity (EC). Correlations between pathogen survival and EC were negative and significant $(\mathrm{P}>0,05)$. In order to evaluate the chemical effects of the sewage sludge on P. nicotianae, water, $\mathrm{H}_{2} \mathrm{SO}_{4} 2 \mathrm{Ne} \mathrm{KOH} 0,4 \mathrm{~N}$ extracts were obtained from sand - sewage sludge $(20 \% \mathrm{w} / \mathrm{w})$ mixtures and each one of them was added to culture medium. The $\mathrm{H}_{2} \mathrm{SO}_{4} 2 \mathrm{~N}$ extract significantly $(\mathrm{P}>0,05)$ inhibited colony growth. The biological effect of the sewage sludge was evaluated by isolating microbial antagonists and testing them against $P$. nicotianae by bioassay and plate techniques. The bioassay technique selected one fungus (isolate F9.1, identified as Aspergillus sp.) and one actinomycete (isolate A12.1, not identified). The plate technique selected one Trichoderma sp. and two actinomycetes for their antibiosis to P. nicotianae, and one Trichoderma sp. and three Aspergillus sp. for their hyper-parasitism to the pathogen.

\section{INTRODUÇÃO}

Entre as doenças fúngicas que afetam os citros ( Citrus spp.), o tombamento, a gomose e a podridão do pé e raízes causadas por Phytophthora spp. estão dentre as de maior

\footnotetext{
* Parte da Dissertação de Mestrado do primeiro autor, a ser apresentada à Escola Superior de Agricultura "Luiz de Queiroz", Universidade de São Paulo. Apoio FAPESP

** Bolsista do CNPq
}

importância econômica ocorrendo em todas as regiões produtoras. No Brasil, as espécies de Phytophthora predominantes são $P$. nicotianae Breda de Haan (1896) (sin. $P$. parasitica Dastur (1913)) e P. citrophthora (R. E. Smith and E. H. Smith) Leonian (1925) (Feichtenberger, 2001).

O manejo das doenças causadas por Phytophthora spp. inclui um conjunto de medidas preventivas e curativas. Dentre elas destacam-se as medidas preventivas nos viveiros para obtenção de mudas sadias; uso de porta-enxertos resistentes; 
e medidas de controle nos pomares, como a escolha de áreas desfavoráveis à doença, adoção de práticas de conservação de solo, uso de adubos orgânicos que favoreçam uma microbiota antagônica ao patógeno, manejo da irrigação e drenagem, monitoramentos freqüentes e controle químico (Erwin \& Ribeiro, 1996; Feichtenberger, 2001). O controle químico pode ser muito eficiente, porém, apesar da dificuldade de desenvolvimento de resistência de fitopatógenos infectantes de raízes a fungicidas, há relatos de resistência de $P$. parasitica a metalaxil (Ferrin \& Kabashima, 1991). Esse problema, associado aos possíveis impactos no agroecossistema, tem levado à busca de alternativas ao controle químico.

Uma alternativa é o uso de matéria orgânica tanto incorporada ao solo, quanto empregada como cobertura e como veículo de agentes de biocontrole, a qual contribui no controle dos patógenos pelo estímulo da atividade microbiana e melhora das características físicas e químicas do solo (Casale et al., 1995; Erwin \& Ribeiro, 1996; Hoitink \& Bohem, 1999). Diversos estudos têm sido realizados para o manejo de Phytophthora spp. com a aplicação ao solo de inúmeras fontes de matéria orgânica (Lumsden et al., 1983; Casale et al., 1995; Erwin \& Ribeiro, 1996; Widmer et al., 1998; Hoitink \& Boehm, 1999).

Atualmente, uma das fontes de matéria orgânica disponível em quantidades crescentes, é o lodo de esgoto proveniente das Estações de Tratamento de Esgotos - ETEs. O lodo constitui um insumo de valor para a agricultura, pois fornece ao solo matéria orgânica, macro e micronutrientes para as plantas, atua como condicionador de solo e fertilizante, e dessa forma, pode contribuir para a obtenção de uma agricultura mais sustentável (Andreoli \& Pegorini, 2000).

O presente trabalho teve o objetivo de avaliar os efeitos da incorporação do lodo de esgoto ao solo na indução de supressividade a $P$. nicotianae em condições de laboratório.

\section{MATERIAL E MÉTODOS}

\section{Isolado de Phytophthora nicotianae e produção de inóculo}

$\mathrm{O}$ isolado IAC $01 / 95$ de $P$. nicotianae utilizado foi fornecido pelo Centro de Citricultura "Sylvio Moreira" Instituto Agronômico de Campinas (CCSM - IAC). O isolado foi mantido em água destilada esterilizada em temperatura ambiente e ausência de luz até sua utilização.

O inóculo foi produzido em grãos de trigo (Triticum aestivum L.) autoclavados em sacos de polipropileno acrescidos com o patógeno. No primeiro dia, sacos de polipropileno de 30 x $40 \mathrm{~cm}$ com $350 \mathrm{~g}$ de grãos de trigo e $200 \mathrm{ml}$ de água destilada foram autoclavados a $121{ }^{\circ} \mathrm{C}$, por $40 \mathrm{~min}$. No segundo dia, foram acrescentados aos sacos mais $150 \mathrm{ml}$ de água destilada e, foram fechados hermeticamente e autoclavados por mais $20 \mathrm{~min}$ a $121^{\circ} \mathrm{C}$. No terceiro dia, sob condições de assepsia, cada saco recebeu 40 discos de $5 \mathrm{~mm}$ de diâmetro de meio de cultura [50 g cenoura (Daucus carotae L.) cozida e triturada no liquificador; $10 \mathrm{~g}$ de dextrose; $16 \mathrm{~g}$ de ágar; água destilada até completar 1 litro) contendo micélio do patógeno das bordas de uma colônia com sete dias de idade.
Finalmente, os sacos foram incubados por quatro ou cinco semanas, em temperatura ambiente, sendo feitas agitações quando necessárias para homogeneizar a colonização dos grãos.

\section{Lodo de esgoto e solo}

O lodo de esgoto foi obtido da Estação de Tratamento de Esgoto (ETE) de Franca, SP. Esse lodo é o produto final do tratamento biológico dos esgotos residenciais, e tem baixos teores de metais pesados (Tabela 1).

O Latossolo vermelho amarelo fase argilosa foi obtido no campo experimental da Embrapa Meio Ambiente (Jaguariúna, SP), com $25 \mathrm{~g} \mathrm{dm}^{2}$ de matéria orgânica e $\mathrm{pH}$ em $\mathrm{CaCl}_{2}$ de 5,1 .

\section{Efeito do lodo de esgoto na sobrevivência in vitro de $\boldsymbol{P}$. nicotianae}

O lodo de esgoto foi misturado ao solo úmido previamente desinfestado em forno de microondas de $900 \mathrm{~W}$ de potência (600 g de solo por $6 \mathrm{~min}$ ), nas proporções de 0 , 10, 20 e 40\% p/p. Cada uma das misturas de solo - lodo de esgoto recebeu o equivalente a 0,10 ou $20 \mathrm{~g}$ de inóculo de $P$. nicotianae $\mathrm{kg}^{-1}$. As misturas foram colocadas em sacos plásticos de 30 x $40 \mathrm{~cm}$ e $100 \mu \mathrm{m}$ de espessura, fechados (mas não hermeticamente) e mantidos a $27^{\circ} \mathrm{C} \pm 2$. Após 21 dias, os sacos foram abertos e a sobrevivência de $P$. nicotianae foi avaliada mediante o teste de iscas de folhas de citros, determinando-se a recuperação do patógeno (porcentagem

TABELA 1 - Análise química do lodo de esgoto empregado nos diferentes experimentos

\begin{tabular}{lr}
\hline Atributo & Valores \\
$\mathrm{pH}$ em água & 6,4 \\
Umidade $\left(65{ }^{\circ} \mathrm{C}\right)$ & 52,1 \\
$\mathrm{C}\left(\mathrm{g} \mathrm{kg}^{-1}\right)$ & 374,4 \\
$\mathrm{~N} \mathrm{Kjeldal}\left(\mathrm{g} \mathrm{kg}^{-1}\right)$ & 50,8 \\
$\mathrm{~N}-\mathrm{amoniacal}\left(\mu \mathrm{g} \mathrm{g}^{-1}\right)$ & 119,5 \\
$\mathrm{~N}-\mathrm{Nitrato}^{-\mathrm{Nitrito}}\left(\mathrm{\mu g} \mathrm{g}^{-1}\right)$ & 54,8 \\
$\mathrm{P}\left(\mathrm{g} \mathrm{kg}^{-1}\right)$ & 21,3 \\
$\mathrm{~K}\left(\mathrm{~g} \mathrm{~kg}^{-1}\right)$ & 0,99 \\
$\mathrm{Ca}\left(\mathrm{g} \mathrm{kg}^{-1}\right)$ & 16,8 \\
$\mathrm{Mg}\left(\mathrm{g} \mathrm{kg}^{-1}\right)$ & 2,5 \\
$\mathrm{~S}\left(\mathrm{~g} \mathrm{~kg}^{-1}\right)$ & 13,3 \\
$\mathrm{~B}\left(\mathrm{mg} \mathrm{kg}^{-1}\right)$ & 7,1 \\
$\mathrm{Cu}\left(\mathrm{mg} \mathrm{kg}^{-1}\right)$ & 359,2 \\
$\mathrm{Fe}\left(\mathrm{mg} \mathrm{kg}^{-1}\right)$ & 31706 \\
$\mathrm{Mn}\left(\mathrm{mg} \mathrm{kg}^{-1}\right)$ & 267,4 \\
$\mathrm{Zn}\left(\mathrm{mg} \mathrm{kg}^{-1}\right)$ & 1590 \\
$\mathrm{Mo}\left(\mathrm{mg} \mathrm{kg}^{-1}\right)$ & $<1$ \\
$\mathrm{Al}\left(\mathrm{mg} \mathrm{kg}^{-1}\right)$ & 33550 \\
$\mathrm{Na}\left(\mathrm{g} \mathrm{kg}^{-1}\right)$ & 0,6 \\
$\mathrm{Ar}\left(\mathrm{mg} \mathrm{kg}^{-1}\right)$ & $<1$ \\
$\mathrm{Cd}\left(\mathrm{mg} \mathrm{kg}^{-1}\right)$ & 2 \\
$\mathrm{Cr}\left(\mathrm{mg} \mathrm{kg}^{-1}\right)$ & 1325 \\
$\mathrm{Hg}\left(\mathrm{mg} \mathrm{kg}^{-1}\right)$ & $<1$ \\
$\mathrm{Ni}\left(\mathrm{mg} \mathrm{kg}^{-1}\right)$ & 74,7 \\
$\mathrm{~Pb}\left(\mathrm{mg} \mathrm{kg}^{-1}\right)$ & 118,8 \\
$\mathrm{Se}\left(\mathrm{mg} \mathrm{kg}^{-1}\right)$ & 0 \\
\hline
\end{tabular}


Efeito do lodo de esgoto na indução de supressividade...

de iscas com zoosporângios nas bordas) e o número de zoosporângios formados nas bordas das iscas. A condutividade elétrica e o $\mathrm{pH}$ das misturas foram também determinados. $\mathrm{O}$ experimento foi repetido duas vezes.

O teste de isca de folhas de citros utilizado foi modificado a partir de Grimm \& Alexander (1973). Em placas de Petri plásticas de $9 \mathrm{~cm}$ de diâmetro, previamente desinfestadas com álcool $70^{\circ}$, foram colocados $5 \mathrm{~g}$ da mistura solo - lodo de esgoto, $30 \mathrm{ml}$ de água destilada e 20 fragmentos de folhas de citros de $3 \times 3 \mathrm{~mm}$ desinfestados com álcool $70^{\circ}$. As placas foram mantidas a $27^{\circ} \mathrm{C} \pm 2$ e luz fluorescente continua por $48 \mathrm{~h}$, quando realizou-se a avaliação das iscas. Para avaliação, as iscas foram observadas no microscópio óptico (aumento de 100 vezes). As folhas empregadas no teste foram obtidas de plantas de laranja que não tinham recebido nenhum tratamento químico.

Para determinar o $\mathrm{pH}$ e a condutividade elétrica, num Erlenmeyer de $100 \mathrm{ml}$ de capacidade foram colocados $10 \mathrm{~g}$ da mistura solo - lodo de esgoto e $25 \mathrm{ml}$ de água destilada deionizada. Foi realizada agitação a $120 \mathrm{rpm}$ por $15 \mathrm{~min}$. Após deixar em repouso por $30 \mathrm{~min}$, procedeu-se a leitura do $\mathrm{pH}$ e da condutividade elétrica do sobrenadante. Para cada repetição foram feitas duas réplicas e três leituras de cada.

Os tratamentos se constituíram da combinação dos fatores doses de lodo $(0,10,20$ e $40 \%$ p/p) e níveis de inóculo (0, 10 ou $\left.20 \mathrm{~g} \mathrm{~kg}^{-1}\right)$, com cinco repetições. Para a análise estatística, os dados de recuperação do patógeno (porcentagem de iscas com zoosporângios nas bordas) foram transformados em arco seno $\sqrt{ } \mathrm{x} / 100$. As correlações entre as variáveis recuperação do patógeno, condutividade elétrica e $\mathrm{pH}$ foram estabelecidas.

\section{Efeito dos extratos do lodo de esgoto no crescimento in vitro de $P$. nicotianae}

Os extratos foram obtidos segundo o método de Widmer et al. (1998) modificado. Foram feitas misturas de $80 \mathrm{~g}$ de areia (lavada, esterilizada e seca) e $20 \mathrm{~g}$ de lodo de esgoto (proporção de $20 \%$ p/p), com $100 \mathrm{ml}$ da solução de $\mathrm{H}_{2} \mathrm{SO}_{4} 2 \mathrm{~N}$, ou $\mathrm{KOH} 0,4 \mathrm{~N}$ ou água bidestilada esterilizada. Como testemunha, foi empregada areia (100 g) com $100 \mathrm{ml}$ de cada uma das soluções. Os Erlenmeyers de $250 \mathrm{ml}$ de capacidade contendo as misturas areia - lodo com as soluções foram agitados manualmente, e a seguir, deixou-se à temperatura ambiente. Após 6 h, filtraram-se as misturas em algodão, seguido de filtragem a vácuo com papel de filtro Whatman 41 e membrana Millipore $0,22 \mu \mathrm{m}$ de porosidade. $\mathrm{O} \mathrm{pH}$ de cada um dos extratos obtidos foi ajustado para valores entre $5,5-6,0$ com soluções de $\mathrm{KOH} 10 \mathrm{~N}$ ou $\mathrm{H}_{2} \mathrm{SO}_{4} 12 \mathrm{M}$. Finalmente, preparou-se meio de cultura de cenoura contendo os diferentes extratos na proporção $9: 1,50 \mathrm{mg} \mathrm{l}^{-1} \mathrm{de}$ rifampicina e $50 \mathrm{mg} \mathrm{l}^{-1}$ de ampicilina, e $15 \mathrm{ml}$ do meio foram vertidos em placas de Petri de $9 \mathrm{~cm}$ de diâmetro. Discos de 5 mm de diâmetro de meio de cultura contendo micélio do patógeno com sete dias de idade, foram transferidos para as placas que foram mantidas a $27{ }^{\circ} \mathrm{C} \pm 2$ e luz fluorescente contínua. Como testemunha utilizaram-se placas contendo meio de cultura com antibióticos e sem extratos. $\mathrm{O}$ efeito dos extratos foi avaliado medindo-se dois diâmetros perpendiculares das colônias, a cada dois dias. Após nove dias de incubação, a área abaixo a curva do crescimento das colônias (AACC) foi calculada. O delineamento experimental foi de parcelas inteiramente casualizadas, com oito repetições.

\section{Isolamento de antagonistas a $P$. nicotianae}

$\mathrm{O}$ isolamento dos microrganismos do solo foi feito mediante diluição seriada e plaqueamento em meios seletivos. Trinta dias após incorporado o lodo de esgoto nas parcelas no campo, foram coletadas amostras do solo dos tratamentos com $0 ; 5 ; 7,5 ; 10$ e $15 \%$ v/v de lodo de esgoto e das parcelas com adubação mineral, com e sem inóculo, resultando num total de 12 amostras compostas. As amostras de solo foram mantidas por dois dias a $25^{\circ} \mathrm{C}$, até sua utilização.

Para o isolamento dos microrganismos foram preparadas suspensões solo - água nas diluições $10^{-1}, 10^{-2}, 10^{-3} \mathrm{e}$ $10^{-4}$, e $100 \mu \mathrm{l}$ de suspensão foram transferidos para meio de cultura. Para o isolamento de bactérias foi empregado o meio de cultura Nutriente ágar - NA (NA Oxoid, $28 \mathrm{~g} \mathrm{r}^{1}$ ) e as diluições $10^{-3}$ e $10^{-4}$. Para o isolamento de actinomicetos foi empregado o meio Amido caseína - AC (10 g amido; 0,3 g de caseína; 2 g $\mathrm{KNO}_{3} ; 2 \mathrm{~g} \mathrm{NaCl} ; 2$ g $\mathrm{K}_{2} \mathrm{HPO}_{4} ; 0,05 \mathrm{~g}$ $\mathrm{MgSO}_{4} \cdot 7 \mathrm{H}_{2} \mathrm{O} ; 0,01 \mathrm{~g} \mathrm{FeSO}_{4} \cdot 7 \mathrm{H}_{2} \mathrm{O} ; 16 \mathrm{~g}$ ágar e 11 água destilada) e as diluições $10^{-3}$ e $10^{-4}$. Para o isolamento de fungos foi empregado o Meio de Martin (1 $\mathrm{g} \mathrm{K}_{2} \mathrm{HPO}_{4} ; 0,5 \mathrm{~g}$ $\mathrm{MgSO}_{4} .7 \mathrm{H}_{2} \mathrm{O} ; 5 \mathrm{~g}$ peptona; $10 \mathrm{~g}$ dextrose; $0,03 \mathrm{~g}$ Rosa de Bengala; 16 g ágar e 11 água destilada) e as diluições $10^{-2} \mathrm{e}$ $10^{-3}$. Foram feitas três repetições para cada combinação meio - diluição, e as placas foram mantidas a $25{ }^{\circ} \mathrm{C}$ até o crescimento das colônias. Foram contadas as colônias por placa, após dois, três ou seis dias para bactérias, fungos e actinomicetos, respectivamente; e foi feita uma seleção por morfologia (tamanho, cor e crescimento) das colônias a serem transferidas a tubos de ensaio contendo $5 \mathrm{ml}$ de meio batata dextrose ágar (BDA) e preservadas a $5{ }^{\circ} \mathrm{C}$ até avaliação do antagonismo ao patógeno.

\section{Avaliação de antagonistas: bioensaio}

Foram testados 35 isolados de bactérias, 32 de actinomicetos e 52 de fungos, segundo o bioensaio descrito por Handelsman et al. (1991) modificado. Sementes de alfafa (Medicago sativa L.) previamente desinfestadas foram colocadas para germinar em caixas contendo papel de germinação umedecido. Após quatro ou cinco dias, as plântulas foram transferidas aos compartimentos das placas de cultura de células (Corning com 24 compartimentos). Em cada compartimento foram colocados $1 \mathrm{ml}$ de água destilada esterilizada, uma plântula de alfafa, um disco de $5 \mathrm{~mm}$ de diâmetro meio de cultura com micélio de $P$. nicotianae e um disco de meio de cultura contendo inóculo do fungo, actinomiceto ou bactéria a ser testado quanto à sua potencialidade como antagonista. As testemunhas foram constituídas por plântulas de alfafa em compartimentos contendo água esterilizada, e plântulas em água esterilizada e $P$. nicotianae. 
As placas foram mantidas por três dias a temperatura ambiente. A avaliação foi feita sob microscópio óptico, onde as raízes das plântulas foram avaliadas pela presença ou não de micélio e zoosporângios de $P$. nicotianae. Para cada isolado (fungo, bactéria ou actinomiceto) foram feitas quatro repetições.

$\mathrm{O}$ crescimento dos microrganismos foi obtido em placas a temperatura ambiente e com diferentes meios: as bactérias em NA e incubadas por $48 \mathrm{~h}$; os fungos em BDA e incubados por uma semana e os actinomicetos em meio AC e incubados por uma semana.

Para determinar a potencialidade de um isolado como antagonista, foram feitas duas escalas de notas que discriminaram níveis de infestação com $P$. nicotianae das plântulas de alfafa crescendo na presença dos diferentes isolados. Para a presença de zoosporângios as notas foram 0
= sem zoosporângios, $1=$ entre 1 e $5,2=$ entre 6 e 10; $3=$ entre 11 e 50, e $4=$ mais de 51. Para a presença de micélio as notas foram $0=$ sem micélio, $1=$ pouco, $2=$ médio, $3=$ muito (Figura 1).

\section{Avaliação de antagonistas: teste de culturas pareadas}

Foram testados sete isolados de fungos, três de actinomicetos e dois de bactérias selecionados no bioensaio quanto ao potencial antagônico a $P$. nicotianae. As condições de crescimento dos microrganismos foram iguais as empregadas no item anterior.

Para o teste em placas Petri de $9 \mathrm{~cm}$ de diâmetro contendo meio BDA foram transferidos um disco de meio de cultura de $5 \mathrm{~mm}$ de diâmetro com micélio de $P$. nicotianae em pleno desenvolvimento e um disco de $5 \mathrm{~mm}$ de diâmetro de meio de cultura com micélio do fungo ou actinomiceto, ou
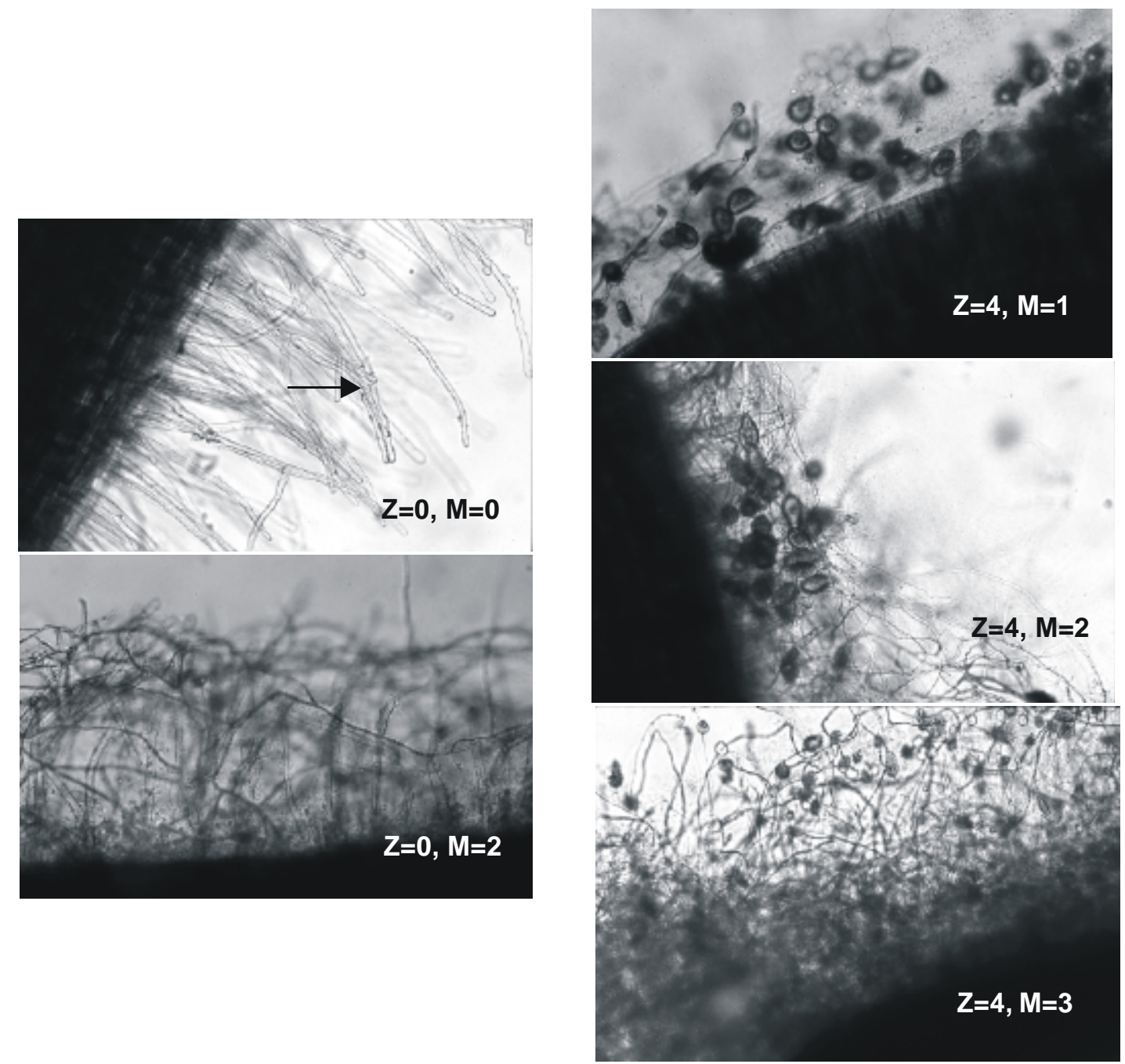

FIG. 1 - Escala de notas empregada na avaliação da potencialidade dos isolados de fungos, actinomicetos e bactérias quanto ao antagonismo a Phytophthora nicotianae, pelo método de infestação de plântulas de alfafa (Medicago sativa). Para a presença de zoosporângios (Z) as notas foram $0=$ sem zoosporângios, $1=$ entre 1 e $5,2=$ entre 6 e 10, $3=$ entre 11 e 50, $4=$ mais de 50. Para a presença de micélio $(M)$ as notas foram $0=$ sem micélio, $1=$ pouco, $2=$ médio, $3=$ muito. A seta indica os pelos absorventes das raízes das plântulas de alfafa. 
Efeito do lodo de esgoto na indução de supressividade...

uma estria do crescimento da bactéria selecionada. As placas foram mantidas a temperatura ambiente até sua avaliação. Foram feitas três repetições por isolado. A avaliação foi feita quanto ao hiperparasitismo (crescimento do antagonista sobre o micélio do patógeno) ou antibiose (inibição do crescimento do patógeno) .

\section{Análises estatísticas}

No presente trabalho, as análises estatísticas foram realizadas empregando o pacote estatístico SAS for Windows, Versão 6.12 do S.A.S Institute, Cory NC, USA

\section{RESULTADOS}

Efeito do lodo de esgoto na sobrevivência in vitro de $\boldsymbol{P}$. nicotianae

Nas condições do laboratório, a sobrevivência de $P$. nicotianae foi menor quando as doses de lodo de esgoto aumentaram nas diferentes misturas solo - lodo de esgoto avaliadas, para os diferentes níveis de inóculo empregados, indicando um possível efeito supressivo do lodo (Figura 2 e Tabela 2). Os valores de $\mathrm{pH}$ das misturas diminuíram quando os níveis de lodo em ausência de inóculo aumentaram; mas na presença de inóculo, primeiro aumentaram e depois diminuíram. Os valores de condutividade elétrica mostraram uma resposta positiva aos incrementos nos níveis de lodo, independente da presença ou não do inóculo (Figura 3 e Tabela 2).

Os coeficientes de correlação (r) da recuperação do patógeno e o número de zoosporângios presentes nas bordas das iscas foram significativos ao $5 \%$ para a condutividade elétrica, mas não para o $\mathrm{pH}$. Os valores de $\mathrm{r}$ foram de $-0,490$ para a porcentagem de recuperação e de $-0,487$ para o número de zoosporângios por borda de isca.

Efeito dos extratos do lodo de esgoto no crescimento in vitro de $P$. nicotianae

Dos extratos avaliados, o extrato ácido do tratamento com $20 \%$ de lodo de esgoto apresentou uma redução significativa no crescimento da colônia de $P$. nicotianae (Tabela 3).

\section{Isolamento de antagonistas a $P$. nicotianae.}

$\mathrm{O}$ número médio de colônias isoladas do solo das parcelas do campo foi da ordem de $10^{6}, 10^{5}$ e $10^{4}$ colônias por grama de solo para bactérias, actinomicetos e fungos, respectivamente. Os tratamentos com e sem lodo tiveram em média valores semelhantes para os diferentes grupos de microrganismos isolados (Tabela 4).

\section{Avaliação de antagonistas a $\boldsymbol{P}$. nicotianae.}

Dos isolados testados no bioensaio, só um fungo (isolado F9.1, do gêneroAspergillus; obtido das parcelas com adubo mineral e inoculadas com $P$. nicotianae) e um actinomiceto (isolado A12.1, não identificado; obtido das parcelas com $15 \%$ de lodo e inoculada) tiveram um controle total de $P$. nicotianae, semelhante à testemunha com água
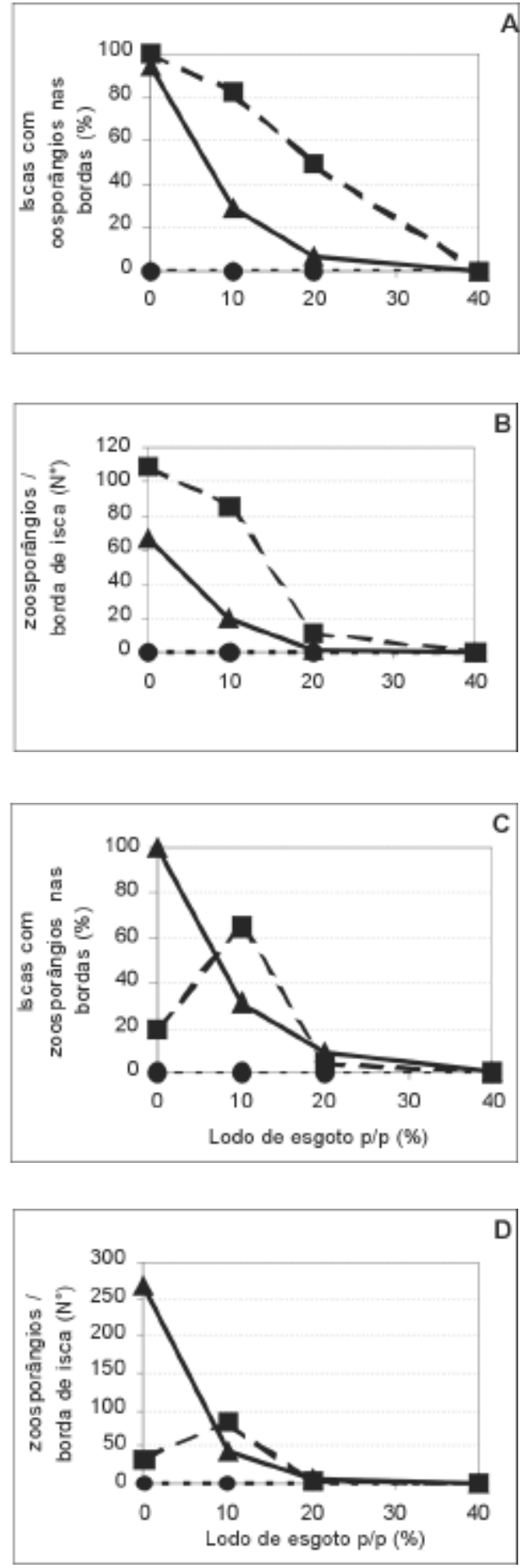

FIG. 2 - Sobrevivência de Phytophthora nicotianae avaliada por meio da porcentagem de recuperação em iscas de folhas de citros (Citrus spp.) e número de zoosporângios por borda de isca, nas diferentes misturas solo - lodo de esgoto, para os diferentes níveis de inóculo (0 -•-, 10 - - e 20 - $\Delta$ - $\mathrm{g} \mathrm{kg}^{-1}$ de mistura), sob condições de laboratório em dois experimentos (gráficos A e B, experimento 1; gráficos C e D, experimento 2). 


\section{Leoni \& R. Ghini}

TABELA 2 - Análise de variância e teste F para as variáveis sobrevivência de Phytophthora nicotianae avaliada por meio da porcentagem de recuperação em iscas de folhas de citros (Citrus spp.) e número de zoosporângios por borda de isca, $\mathrm{pH}$ e condutividade elétrica (CE) nas diferentes misturas solo lodo de esgoto $\left(0,10,20\right.$ e $40 \%$ p/p), para os diferentes níveis de inóculo $\left(0,10\right.$ e $20 \mathrm{~g} \mathrm{~kg}^{-1} \mathrm{de}^{\mathrm{a}}$ mistura), sob condições de laboratório em dois experimentos

\begin{tabular}{|c|c|c|c|c|c|c|c|}
\hline \multirow{3}{*}{ Causa da variação } & \multirow{3}{*}{ GL } & \multicolumn{6}{|c|}{ QM } \\
\hline & & \multicolumn{2}{|c|}{ Recuperação (\%) } & \multicolumn{2}{|c|}{ Zoosporângios por borda $\left(\mathbf{N}^{\circ}\right)$} & \multicolumn{2}{|c|}{ Experimento 2} \\
\hline & & Exp. 1 & Exp.2 & Exp. 1 & Exp.2 & pH & $\mathbf{C E}$ \\
\hline Lodo & 3 & $8749,8 *$ & $4058,5 *$ & $120,8 *$ & $143,4 *$ & $1,49 *$ & $927405,4 *$ \\
\hline Inóculo & 2 & $13061,5 *$ & $4933,6 *$ & $154,6 *$ & $151,3 *$ & $1,95 *$ & $168352,0 *$ \\
\hline Lodo $\mathrm{x}$ inóculo & 6 & $2675,0 *$ & $2400,8 *$ & $38,9 *$ & $69,5 *$ & $0,72 *$ & $32558,5 *$ \\
\hline Resíduo & 36 & 224,7 & 67,3 & 1,9 & 1,7 & 0,0001 & 18,3 \\
\hline $\mathrm{CV}(\%)$ & & 56,1 & 42,8 & 48,8 & 39,7 & 0,65 & 0,86 \\
\hline $\mathrm{R}^{2}$ & & 0,86 & 0,94 & 0,91 & 0,95 & 0,99 & 0,99 \\
\hline
\end{tabular}

* significativo pelo teste de $\mathrm{F}$, ao nível de $1 \%$ de probabilidade.
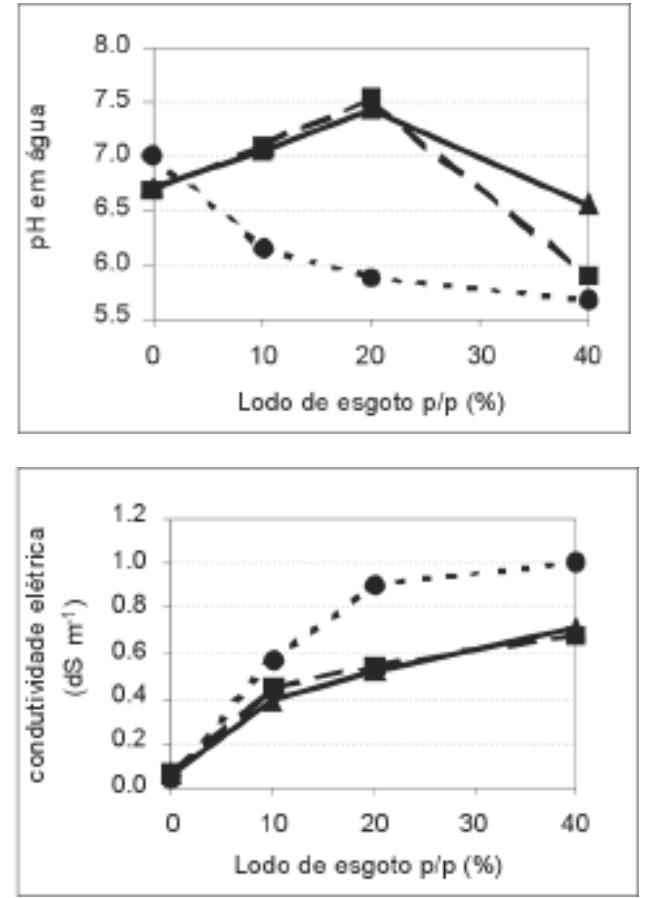

FIG. 3 - Efeito do lodo de esgoto no pH em água e na condutividade elétrica (CE) da solução das misturas solo - lodo de esgoto, nas diferentes misturas solo lodo de esgoto, para os diferentes níveis de inóculo $0 \rightarrow-, 10-\square-$ e $20 \wedge-\mathrm{g} \mathrm{kg}^{-1}$ de mistura), sob condições de laboratório, no experimento 2.

destilada esterilizada, onde as plântulas de alfafa não apresentaram nem zoosporângios nem micélio. Sete isolados de fungos, três de actinomicetes e dois de bactérias permitiram o desenvolvimento de micélio, mas não dos zoosporângios. Alguns isolados tiveram um comportamento semelhante à testemunha com água e $P$. nicotianae (Tabela 5).

Dos isolados avaliados mediante o teste de pareamento de colônias, destacaram-se cinco fungos e dois actinomicetos. Um fungo do gênero Trichoderma (isolado F8.3/4; obtido das parcelas com adubo mineral e inoculada) destacou-se por antibiose com formação de halo de inibição de $1 \mathrm{~cm}$; e os outros quatro, um Trichoderma sp. (isolado F12.3; obtido das parcelas com 15\% de lodo e inoculada) e três Aspergillus spp. (isolado F8.10 obtido das parcelas com adubo mineral e inoculada; e isolados F9.1, F11.1; obtidos das parcelas com 5 e $10 \%$ de lodo e inoculadas, respectivamente) por hiperparasitismo, com crescimento micelial recobrindo toda a placa em 72 h. Os dois actinomicetos (isolados A2.1 e A12.1; obtido das parcelas com adubo mineral e sem inóculo, e com $15 \%$ de lodo e inoculada, respectivamente) também desenvolveram halos de inibição de $1 \mathrm{~cm}$. Os isolados que não interferiram nem com o crescimento nem com a esporulação de $P$. nicotianae foram as bactérias (isolados B10.6 e B11.1), um actinomiceto (isolado A9.7) e dois fungos (F10.4 e F10.8).

\section{DISCUSSÃO}

A supressividade a $P$. nicotianae foi diretamente proporcional à concentração de lodo de esgoto incorporado no solo (Figura 2). Esses resultados são coincidentes com os obtidos por outros autores, tanto para o manejo das doenças causadas por Phytophthora spp. Como por outros patógenos, em diversas culturas (Lumsden et al., 1983; Bettiol \& Krugner, 1984; Lewis et al., 1992; Casale et.al., 1995; Widmer et al., 1998; Hoitink \& Boehm, 1999).

Dentre os fatores que podem explicar a supressividade a $P$. nicotianae, a presença de compostos tóxicos devido aos processos de decomposição da matéria orgânica adicionada ao solo é uma delas. Esses efeitos têm sido reportados por vários autores para diversos patógenos, usando diferentes fontes de matéria orgânica (Hoitink et al., 1977; Casale et al., 1995; Blok et al., 2000). No presente trabalho, foram obtidas inibições do crescimento in vitro de colônias do patógeno quando colocado a crescer em meio de cultura acrescentado com extratos ácidos (Tabela 3), coincidente com os resultados obtidos por Widmer et al. (1998), sugerindo um possível efeito químico na indução de supressividade.

Nos experimentos realizados, quando se usaram as doses de inóculo maiores, os valores de recuperação da $P$. 
Efeito do lodo de esgoto na indução de supressividade...

TABELA 3 - Diâmetros médios das colônias de Phytophthora nicotianae isolado IAC 01/ 95 aos quatro e nove dias após repicagem, e área abaixo da curva de crescimento das colônias aos nove dias (AACC), crescendo em meio de cenoura (Daucus carotae) (MC) contendo extratos aquosos, ácidos $\left(\mathrm{H}_{2} \mathrm{SO}_{4}\right)$ ou básicos $(\mathrm{KOH})$ de lodo de esgoto (LE) em areia

\begin{tabular}{|c|c|c|c|c|c|c|}
\hline \multirow{2}{*}{ Tratamento } & \multicolumn{4}{|c|}{ Dias após repicagem } & \multirow{2}{*}{\multicolumn{2}{|c|}{$\mathrm{AACC}$}} \\
\hline & & 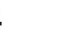 & 9 & & & \\
\hline Testemunha (MC) & $5,43^{1}$ & $a b^{2}$ & $9,00^{1}$ & $\mathrm{a}$ & 52,56 & $\mathrm{a}$ \\
\hline Areia + água & 5,40 & $\mathrm{ab}$ & 9,00 & $\mathrm{a}$ & 52,18 & $\mathrm{a}$ \\
\hline Areia $+\mathrm{KOH}$ & 4,41 & $\mathrm{c}$ & 8,82 & $\mathrm{a}$ & 44,61 & b \\
\hline Areia $+\mathrm{H}_{2} \mathrm{SO}_{4}$ & 4,63 & $\mathrm{c}$ & 8,65 & $\mathrm{a}$ & 45,52 & b \\
\hline Areia + LE + água & 4,89 & bc & 8,73 & $\mathrm{a}$ & 47,86 & $\mathrm{~b}$ \\
\hline Areia + LE + KOH & 5,68 & $\mathrm{a}$ & 9,00 & $\mathrm{a}$ & 53,44 & $\mathrm{a}$ \\
\hline Areia $+\mathrm{LE}+\mathrm{H}_{2} \mathrm{SO}_{4}$ & 2,05 & $\mathrm{~d}$ & 2,27 & $\mathrm{~b}$ & 17,28 & $\mathrm{c}$ \\
\hline
\end{tabular}

${ }^{1}$ Diâmetro médio das colônias em $\mathrm{cm}$.

${ }^{2}$ Dados seguidos da mesma letra, na coluna, não diferem significativamente (Teste de Duncan, ao nível de 5\% de probabilidade).

nicotianae foram menores, contrariamente ao esperado (Figura 2). Isto poderia ser explicado pelo tipo de inóculo empregado, grãos de trigo colonizados, os quais ao serem incorporados ao solo também são degradados e podem liberar substâncias tóxicas à $P$. nicotianae, incidindo negativamente em sua sobrevivência.

Um segundo fator que pode explicar a supressividade a $P$. nicotianae são os valores de condutividade elétrica obtidos quando o lodo de esgoto foi incorporado ao solo ou substrato (Figura 2). Lapeña et al. (2000) observaram que sob condutividade elétrica de até $5 \mathrm{dS} \mathrm{m}^{-1}$ por $24 \mathrm{~h}$, a viabilidade, e consequentemente a capacidade de infetar, dos zoosporângios de $P$. citrophthora diminuiu. Semelhantemente ao presente trabalho, Workneh et al. (1993) estabeleceram correlações negativas entre condutividade elétrica e presença de $P$. parasitica ou incidência da doença em plantas de tomateiro (Lycopersicon esculentum Mill.).

Um terceiro fator que pode explicar a supressividade a $P$. nicotianae, é o aumento da atividade microbiana do solo, onde as populações microbianas estabeleceriam um controle biológico mediante os mecanismos de competição, antibiose, parasitismo e indução de resistência (Hoitink \& Boehm, 1999).
Malacjzuck (1983) sugere que os principais mecanismos envolvidos no controle de Phytophthora spp. são competição por nutrientes e antibiose. Downer et al. (2001) sugerem que a produção de celulase e laminarinase é o principal mecanismo envolvido na supressividade a P. cinnamomi Rands. nosistema Ashburner, destruindo zoósporos e outros propágulos do patógeno; e afirmam que as enzimas são produzidas pela comunidade de fungos, entre elesPenicillium sp. eAspergillus sp., e que essa atividade enzimática é favorecida por valores de $\mathrm{pH}$ baixos.

A incorporação do lodo de esgoto ao solo não alterou as comunidades de fungos, actinomicetos e bactérias do solo, quando avaliada mediante a contagem de colônias em placas (Tabela 4), resultado coincidente com Lewis et al. (1992). Entretanto, Millner et al. (1981) constataram o aumento das comunidades de bactérias e actinomicetos como resposta à incorporação de lodo de esgoto, e Pascual et al. (2000) das comunidades de bactérias e fungos quando incorporaram composto de lixo urbano, com aumento das populações de pseudomonas fluorescentes e Trichoderma spp. Downer et al. (2001) obtiveram uma resposta variável dependendo do meio de cultura empregado para avaliar as comunidades microbianas dos solos com e sem cobertura, constatando mudanças nas populações de fungos saprófitas quando avaliadas em meio com Rosa de Bengala, e identificaram basidiomicetos crescendo sobre a cobertura que não foram isolados em nenhum dos meios de cultura. Os solos com cobertura tiveram uma maior diversidade de gêneros de fungos, dentre eles Penicillium, Aspergillus, Trichoderma (o qual não foi isolado dos solos sem cobertura ).

Diversas espécies do gênero Trichoderma são bem conhecidas como agentes de controle biológico de doenças causadas por Phytophthora spp. (Malajczuk, 1983; Casale et al., 1995; Costa et al., 1996; Ahmed et al, 1999), mas também fungos do gêneroAspergillus (Sztejnberg \& Tsao, 1986 citado por Fang \& Tsao, 1995) e actinomicetos possuem capacidade de produção de antibióticos (Malajczuk, 1983; You et al., 1996).

Devido à complexidade dos processos envolvidos, para determinar o impacto potencial do agregado de matéria orgânica ao solo na indução de supressividade aos diferentes patógenos, são necessários estudos locais, nos solos e com as fontes de matéria orgânica disponíveis na região. Embora o

TABELA 4 - Comunidades de fungos, actinomicetos e bactérias (unidades formadoras de colonias - ufc) isoladas do solo das parcelas do campo com e sem inóculo de Phytophthora nicotianae isolado IAC 01/95, aos 28 dias após inoculação, nos diferentes tratamentos de solo sem lodo e com adubo mineral $(0+A)$, ou com incorporação de lodo de esgoto nas proporções 0; 7,5; 10 e 15\% v/v

\begin{tabular}{|c|c|c|c|c|c|c|c|}
\hline \multirow{2}{*}{ Organismo } & \multirow{2}{*}{ Tipo de solo } & \multicolumn{6}{|c|}{ Tratamentos do solo (\% lodo v/v) } \\
\hline & & $\mathbf{0}+\mathbf{A}$ & $\mathbf{0}$ & 5 & 7,5 & 10 & 15 \\
\hline Fungos & Sem inóculo & 4,17 & 4,94 & 4,57 & 4,67 & 4,42 & 4,01 \\
\hline$\left(\right.$ ufc. g solo $\left.^{-1}\right)$ & Com inóculo & 4,75 & 4,97 & 4,43 & 4,62 & 4,49 & 4,49 \\
\hline Actinomicetos & Sem inóculo & 5,27 & 5,60 & 5,41 & 5,43 & 5,31 & 5,39 \\
\hline$\left(\right.$ ufc. $\left.\mathrm{g} \mathrm{solo}^{-1}\right)$ & Com inóculo & 5,47 & 4,11 & 5,42 & 5,17 & 5,26 & 5,44 \\
\hline Bactérias & Sem inóculo & 6,35 & 7,21 & 7,24 & 7,17 & 7,67 & 7,31 \\
\hline$\left(\right.$ ufc. $\left.\mathrm{g} \mathrm{solo}^{-1}\right)$ & Com inóculo & 6,84 & 7,32 & 6,82 & 6,89 & 6,98 & 7,44 \\
\hline
\end{tabular}

Fitopatol. bras. 28(1), jan - fev 2003 
TABELA 5 - Potencialidade de alguns isolados de fungos, actinomicetos e bactérias quanto ao antagonismo a Phytophthora nicotianae, pelo método de infestação de plântulas de alfafa (Medicago sativa)

\begin{tabular}{|c|c|c|c|}
\hline \multirow{2}{*}{$\begin{array}{l}\text { Nível de infestação } \\
\text { com } P \text {. nicotianae das } \\
\text { plântulas de alfafa }\end{array}$} & \multicolumn{3}{|c|}{ Isolados } \\
\hline & Fungos & Actinomicetos & Bactérias \\
\hline$Z=0$ e $\quad M=0^{1,2}$ & F9. $1^{3}$ & A12.1 & ---- \\
\hline $\mathrm{Z}=\mathbf{0}$ & $\begin{array}{c}\text { F9.1, F11.1, F10.4, F10.8, F8.3/4, } \\
\text { F12.3, F8.10 }\end{array}$ & A12.1, A9.7, A2.1 & B11.1, B10.6 \\
\hline $\mathrm{Z}<\mathbf{0 , 7 5}$ e $\mathrm{M}<1,0$ & $\begin{array}{c}\text { F9.1, F10.4, F4.1, F2.1, F8.10, } \\
\text { F7.1, F10.1, F8.3/2 }\end{array}$ & $\begin{array}{l}\text { A12.1, A3.2, A4.2, A6.6, A4.1b, } \\
\text { A6.1, A9.7, A2.1, A6.5, A6.4 }\end{array}$ & B11.5, B11.1, B11.3, B10.10 \\
\hline $\mathrm{Z}>\mathbf{3 , 0}$ & $\begin{array}{c}\text { F5.3, F2.2, F3.5, F10.5, F4.7, } \\
\text { F10.9, F4.4, F10.3 }\end{array}$ & A3.1, A9.6 & $\begin{array}{c}\text { B10.2, B10.3, B11.2, B1.6, } \\
\text { B10.11,B11.4, B11.8, B11.6, B1.10, } \\
\text { B1.1, B1.13, B10.4, B10.1, B10.12, } \\
\text { B1.8, B1.5, B10.9 }\end{array}$ \\
\hline \multicolumn{4}{|c|}{$\begin{array}{l}{ }^{1} \mathrm{Z}=\mathrm{N}^{\circ} \text { de zoosporângios por plântula, } 0=\text { sem zoosporângios, } 1=1 \text { a } 5 ; 2=6 \text { a } 10 ; 3=11 \text { a } 50,4=>51 ; \mathrm{M}=\text { presença de micélio de } \text { Phytophthoranicotianae nas } \\
\text { plântulas, } 0=\text { sem micélio, } 1=\text { pouco, } 2=\text { médio, } 3=\text { muito. } \\
{ }^{2} \text { médias de quatro repetições } \\
{ }^{3} \text { A primeira letra do nome do isolado corresponde ao grupo de microrganismo (F: fungos, A: actinomicetos e B: bactérias). O primeiro número do nome do isolado } \\
\text { corresponde ao tratamento: } 1=\text { parcelas sem lodo e sem inóculo de } \text { Phytophthora nicotianae, } 2=\text { com adubo mineral e sem inóculo, } 3=\text { com } 5 \% \text { de lodo e sem } \\
\text { inóculo, } 4=\text { com } 7,5 \% \text { de lodo e sem inóculo, } 5=\text { com } 10 \% \text { de lodo e sem inóculo, } 6=\text { com } 15 \% \text { de lodo e sem inóculo, } 7=\text { sem lodo e com inóculo, } 8=\text { com adubo } \\
\text { mineral e com inóculo, } 9=\text { com } 5 \% \text { de lodo e com inóculo, } 10=\text { com } 7,5 \% \text { de lodo e com inóculo, } 11=\text { com } 10 \% \text { de lodo e com inóculo, } 12=\text { com } 15 \% \text { de lodo e com } \\
\text { inóculo. }\end{array}$} \\
\hline
\end{tabular}

bioensaio empregado no presente trabalho tenha mostrado capacidade na seleção de isolados, não se deve esquecer a necessidade de testar estes isolados em planta e sob diferentes condições de crescimento das mesmas, assim como a sua sobrevivência no solo.

\section{REFERÊNCIAS BIBLIOGRÁFICAS}

AHMED, A.S., PEREZ-SANCHEZ, C., EGEA, C. \& CANDELA, M.E. Evaluation of Trichoderma harzianum for controlling root rot caused by Phytophthora capsici in pepper plants. Plant Pathology 48:58-65. 1998.

ANDREOLI, C.V.\& PEGORINI, E.S. Gestão pública do uso agrícola do lodo de esgoto. In: Bettiol, W. \& Camargo, O. A. (Eds). Impacto ambiental do uso agrícola do lodo de esgoto. Jaguariúna: Embrapa Meio Ambiente. 2000. pp: 281-312.

BETTIOL, W. \& KRUGNER, T.L. Influência do lodo de esgoto na severidade da podridao de raíz do sorgo causada por Pythium arrhenomanes. Summa Phytopathologica 10:243-251. 1984.

BLOK, W.J., LAMERS, J.G., TERMORSHUIZEN, A.J. \& BOLLEN, G.J. Control of soilborne plant pathogens by incorporating fresh organic ammendments followed by tarping. Phytopathology 90:253-259. 2000.

CASALE, W.L., MINASSIAN, V., MENGE, J.A., LOVATT, C.J., POND, E., JOHNSON, E. \& GUILLEMET, F. Urban and agricultural wastes for use as mulches on avocado and citrus and for delivery of microbial biocontrol agents. Journal of Horticultural Science 70:315352. 1995.

COSTA, J.L. da; MENGE, J.A. \& CASALE, W.L. Investigations on some of the mechanisms by wich bioenhaced mulches can supress Phytophthora root rot of avocado. Microbiological Research 151:183192. 1996.

DOWNER, A.J., MENGE, J.A. \& POND, E. Association of cellulolytic enzyme activities in eucalyptus mulches with biological control of Phyophthora cinnamomi. Phytopathology 91:847-855. 2001.

ERWIN, D.C. \& RIBEIRO, O.K. Phytophthora diseases worldwide. St. Paul: APS Press, 1996.

FANG, J.G. \& TSAO, P.H. Efficacy of Penicillum funiculosum as a biological control agent against phytophthora root rots of azalea and citrus. Pyhtopathology 85:871-878. 1995.

FEICHTENBERGER, E. Doenças incitadas por Phytophthora em citros. In: Luz, E.D.M.N., Santos, A.F., Matsuoka, K. \& Bezerra, J.L. (Eds.). Doenças causadas por Phytophthora no Brasil. Campinas. Livraria Rural. 2001. pp.283-342.

FERRIN, D.M. \& KABASHIMA, J.N. In vitro insensitivity to metalaxyl of isolates of Phytophthora citricola and P. parasitica from ornamental hosts in southern California. Plant Disease 75:10411044. 1991.

GRIMM, G.R. \& ALEXANDER, A.F. Citrus leaf pieces as traps for Phytophthora parasitica from soil slurries. Phytopathology 63:540-541. 1973.

HANDELSMAN, J., NESMITH, W.C. \& RAFFEL, S.J. Microassay for biological control of infection of tobacco by Phytophthora parasitica var. nicotianae. Current Microbiology 22:317-319. 1991.

HOITINK, H.A.J., VAN DOREN, D.M. \& SCHMITTHENNER, A.F. Suppression of Phytophthora cinnamomi in a compostes hardwood bark potting medium. Phytopathology 67:561-565. 1977. HOITINK, H.A.J. \& BOEHM, M.J. Biocontrol within the context of soil microbial comunities: a substrate dependent phenomenon. Annual Review of Phytopathology 37:427-446. 1999.

LAPEÑA, I., TUSET, J.J., HINAREJOS, C. \& MIRA, J.L. Interacción entre la conductividad eléctrica de la solucióndel suelo y la infección de Phytophthora citrophthora en plántulas de cinco portainjertos de cíticos. Resúmenes, $10^{\circ}$ Congreso de la Sociedad 
Efeito do lodo de esgoto na indução de supressividade...

Española de Fitopatología, Valencia. 2000. p.218.

LEWIS, J.A., LUMSDEN, R.D., MILLNER, P.D. \& KEINATH, A.P. Suppression of damping-off of peas and cotton in the field with composted sewage sludge. Crop Protection 11:260-266. 1992.

LUMSDEN, R.D., LEWIS, J.A. \& MILLNER, P.D. Effect of composted sewage sludge on several soilborne pathogens and diseases. Phytopathology 73:1543-1548. 1983.

MALAJCZUK, N. Microbial antagonism to Phytophthora. In: Erwin, D.C., Bartnicki - Garcia, S. \& Tsao, P.H. (Eds). Phytophthora. Its biology, taxonomy, ecology and pathology. St. Paul, APS Press. 1983. pp. 197-218.

MILLNER, P.D., LUMDSEN, R.D. \& LEWIS, J.A. Controlling plant disease with sludge compost. BioCycle 22:50-52. 1981

PASCUAL, J.A., HERNANDEZ, T., GARCIA, C., DE LEIJ,
F.A.A.M. \& LYNCH, J.M. Long-term suppression of Pyhium ultimum in arid soil using fresh and composted municipal wastes. Biology and Fertility of Soils 30:478-484. 2000.

WIDMER, T.L., GRAHAM, J.H. \& MITCHELL, D.J. Composted municipal waste reduces infection of citrus seedlings by Phytophthora parasitica. Plant Disease 82:683-688. 1998.

WORKNEH, F., VAN BRUGGEN, A.H.C., DRINKWATER, L.E. \& SHENNAN, C. Variables associates with corky root and Phytophthora root rot of tomatoes in organic and conventional farms. Phytopathology 83:581-589. 1993.

YOU, M.P., SIVASITHAMPARAM, K., KURTBÖKE. Actinomycetes in organic mulch used in avocado plantations and their ability to supress Phytophthora cinnamomi. Biology and Fertility of Soils 22:237-242. 1996. 